Review

\title{
Lipid Self-Assemblies and Nanostructured Emulsions for Cosmetic Formulations
}

\author{
Chandrashekhar V. Kulkarni \\ Centre for Materials Science, School of Physical Sciences and Computing, University of Central Lancashire, \\ Preston PR1 2HE, UK; cvkulkarni@uclan.ac.uk; Tel.: +44-1772-89-4339; Fax: +44-1772-89-4981 \\ Academic Editor: Lisa A. DeLouise \\ Received: 2 September 2016; Accepted: 26 October 2016; Published: 31 October 2016
}

\begin{abstract}
A majority of cosmetic products that we encounter on daily basis contain lipid constituents in solubilized or insolubilized forms. Due to their amphiphilic nature, the lipid molecules spontaneously self-assemble into a remarkable range of nanostructures when mixed with water. This review illustrates the formation and finely tunable properties of self-assembled lipid nanostructures and their hierarchically organized derivatives, as well as their relevance to the development of cosmetic formulations. These lipid systems can be modulated into various physical forms suitable for topical administration including fluids, gels, creams, pastes and dehydrated films. Moreover, they are capable of encapsulating hydrophilic, hydrophobic as well as amphiphilic active ingredients owing to their special morphological characters. Nano-hybrid materials with more elegant properties can be designed by combining nanostructured lipid systems with other nanomaterials including a hydrogelator, silica nanoparticles, clays and carbon nanomaterials. The smart materials reviewed here may well be the future of innovative cosmetic applications.
\end{abstract}

Keywords: lipid self-assembly; lipid nanostructures; cosmetics; formulations; oil-in-water emulsions; water-in-oil emulsions; hierarchically ordered materials; nano-hybrids

\section{Introduction}

The cosmetic product, according to the EU regulation, is defined as "any substance or mixture intended to be placed in contact with the external parts of the human body (epidermis, hair system, nails, lips and external genital organs) or with the teeth and the mucous membranes of the oral cavity with a view exclusively or mainly to cleaning them, perfuming them, changing their appearance, protecting them, keeping them in good condition or correcting body odours" [1]. There are about 25,000 ingredients that constitute cosmetic products, most of which can be grouped into oils, waxes, and fats-broadly defined as "lipids" [2]. Natural sources (e.g., plants and animal) still appear to be the preferred means of obtaining these ingredients over synthetic derivatives [2].

Lipids form an integral part of cosmetic products [3-6]. Their cosmetic applications are fundamentally determined by their physico-chemical properties. For instance, due to hydrophobic nature, they can act as a barrier against water-loss from the skin. Their viscosity and semi-solid consistency defines the spreadability, which is an important factor to fill small indentations on the skin surface imparting smooth and shiny appearance. Not only the melting point, but also the phase behavior of a lipid is crucial for the stability and performance of the cosmetic product. Lipids form a remarkable range of self-assembled nanostructures exhibiting very different architectures and properties to each other. Therefore, if the lipid phase behavior at a range of temperatures and water contents is known, it is possible to control the properties and performance of the cosmetic products during their processing, storage, transport and final applications. This review describes the types of lipid nanostructures, their derivatives with improved performance and possible ways to fine-tune their properties that can influence the development of cosmetic formulations. 


\section{Lipid Self-Assembly: Simple and Elegant Nanostructures}

Among over 40,000 unique lipid structures known to date, fatty acyls and glycerides comprise more than half [7] (Figure 1). These lipids are also common for an extensive range of cosmetic products [2]. Lipids are generally amphiphilic in nature-amphi means two and philic means liking or loving. The lipid molecule has two parts: the hydrophilic head group, which likes water and long alkyl chain/s, which do not like water. This special chemistry governs the self-assembling process of lipids when mixed with an aqueous medium [8-11].

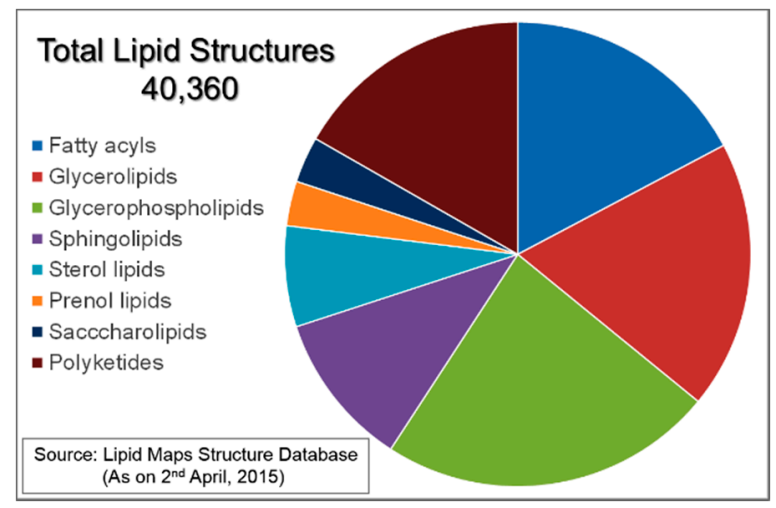

Figure 1. Main categories of lipid structures deposited on Lipid Maps Structure Database [7].

An average shape of the amphiphilic molecule determines the type of self-assembly (Figure 2) [11,12]. Molecules with large hydrophilic groups, e.g., detergents, tend to form normal (type 1) self-assemblies while rather small head group molecules, e.g., lipids, have a tendency to form inverse (type 2) phases. Biological membranes constitute a large assortment of different shaped molecules having a tendency to form dynamic self-assemblies including locally planar structures (type 0). Spherical micelles and cylindrical micelles are simple self-assemblies formed in both normal and inverse types, whereas lamellar phase is formed when the molecule acquires straight (average) shape (Figure 2). Vesicles (liposomes) are also formed in this situation, as, at local level, they exhibit planar lamellar phase.

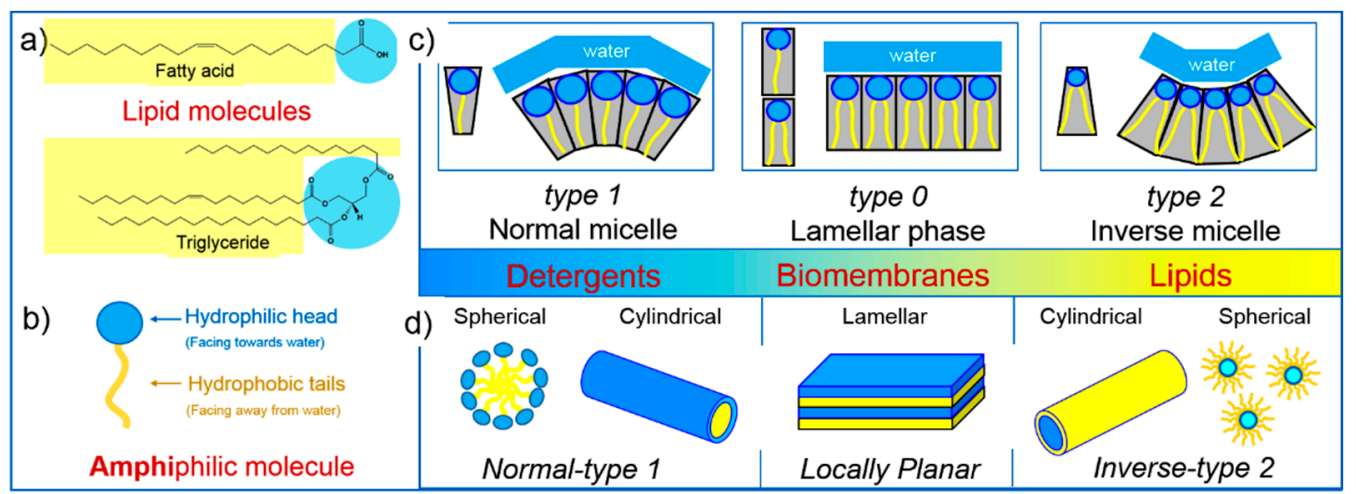

Figure 2. (a) Chemical structures of typical lipid molecules; (b) Schematic diagram of an amphiphilic molecule where blue and yellow colors roughly code for hydrophilic and hydrophobic parts of the molecule; (c) Average molecular shapes and process of self-assembling of amphiphilic molecules when they are mixed with water; (d) Schematics of simple self-assemblies formed by amphiphilic molecules.

Vesicles, also called liposomes, are formed when a single or multiple lipid bilayers organize into a spherical shape to enclose the water (Figure 3) [13]. However, the shape is not always spherical; 
vesicles take a range of shapes and are hence given corresponding names, such as prolate or starfish vesicles [14]. If the vesicle is formed of a single bilayer, it is called a uni-lamellar vesicle (ULV). Similarly, if it constitutes multiple bilayers, it is called a multi-lamellar vesicle (MLV) (Figure 3). Sometimes, a large vesicle engulfs similar or different sized smaller vesicles, it is called oligo-vesicular vesicle (OVV) [14]. Based on their size uni-lamellar vesicles are broadly categorized into small (SUV, 10-100 nm), large (LUV, 100-1000 nm) and giant (GUV, >1 $\mu \mathrm{m}$ ) uni-lamellar vesicles [15] (Figure 3). These vesicles are highly popular among biotechnological researchers due to their prominent applications, including model membranes [16] and drug delivery carriers [17].

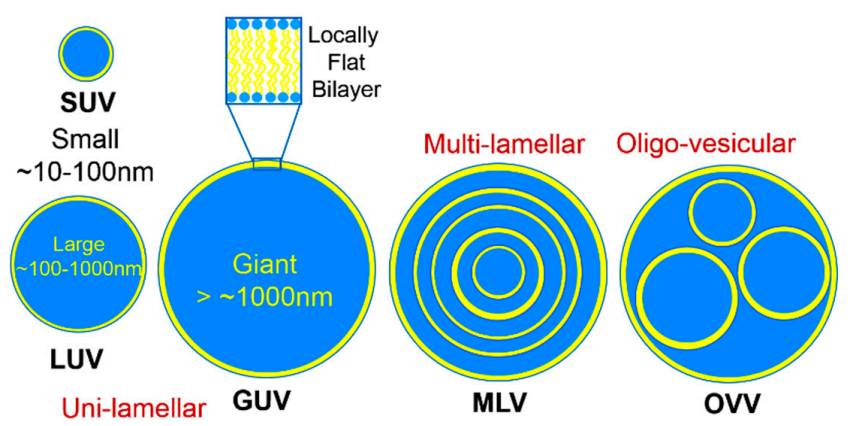

Figure 3. Types and schematic diagrams of vesicles (liposomes).

Much more elegant and complex morphologies are formed by lipids under various environmental factors in zero-, one-, two- and three-dimensional space (Figure 4). The spatial arrangement of these lipid phases mediates crystalline solids and Newtonian liquids, hence they are often termed as liquid crystalline (LC) phases. However, they are getting more recognition as "nanostructures" due to several representative properties: their unit cell sizes scale in the range of $0.25-35 \mathrm{~nm}[15,18]$ and the lipid bilayer thickness for cubic phases lies in 2.0-6.2 nm length scale [18]; whereas aqueous channel diameters for bicontinuous cubic phases can be anywhere between $1.0 \mathrm{~nm}$ and $13.0 \mathrm{~nm}$ [18].

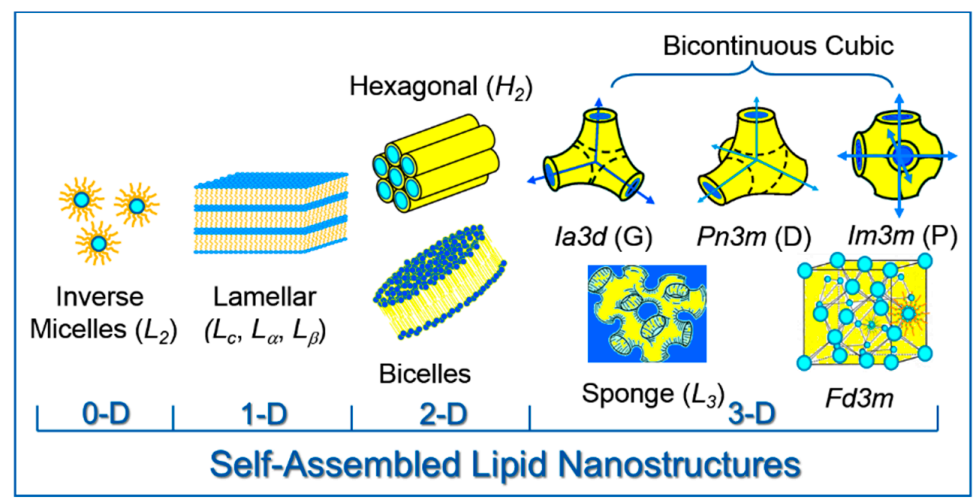

Figure 4. Types and schematic diagrams of thermodynamically stable self-assembled lipid nanostructures.

In dry state or low hydration and/or temperatures, lipids tend to form crystalline lamellar phase $\left(L_{c}\right)$ due to restricted molecular motion. With further increase in temperature and/or hydration they may modify into various polymorphs, for instance, lamellar gel $\left(L_{\beta}\right)$, fluid lamellar $\left(L_{\alpha}\right)$ or simply inverse micelles $\left(L_{2}\right)$ [8,19]. The lamellar phase is usually formed by one-dimensional (1-D) stacking of lipid bilayers separating adjacent hydrophilic (water) layers; each such bilayer is formed by two back-to-back monolayers shielding the hydrocarbon chains away from water (Figure 4). Lipids in stratum corneum of human skin form highly ordered layers adopting lamellar nanostructures [20]. Small angle X-ray diffraction studies revealed the lamellar repeat spacing in the range of $60-65 \AA$, 
while the lipid head group packing displayed crystalline and fluid lamellar polymorphs with wide angle reflections at 4.0-4.2 $\AA$ (many sharp reflections) and $4.6 \AA$ (broad reflection), respectively [20]. This structured lipid layer helps skin to withstand desiccation and thermal regulation. The triglyceride triacylglycerol (TAG) lipids exhibit additional range of polymorphism (further types of crystalline and gel polymorphs) generally seen in the structure of foods [21,22]. TAGs are very common lipids employed in cosmetic formulations [3,6], displaying a broad lamellar phase behaviour discussed above.

The inverse hexagonal phase $\left(\mathrm{H}_{2}\right)$ is a common non-lamellar phase formed by many lipids [10]. It consists of aqueous conduits enclosed within two-dimensional (2-D) cylindrical lipid architectures (Figure 4). The $\mathrm{H}_{2}$ phase formed during the transient re-assembly of lipids in stratum corneum is presumed to form an effective barrier against water transport similar to lamellar nanostructures [20]. The bicelle is a 2-D nanostructure formed from a small bilayer taking the shape of a disk (Figure 4). It is usually formed by a mixture of more than one lipid (or similar) components [23]. The structure of the bicelle mediates the morphology of vesicles and conventional mixed micelles, thereby offering an attractive model membrane properties [23].

Three-dimensional (3-D) and elegant nanostructures include following lipid phases: bicontinuous cubic phases, sponge phase and micellar cubic phases (Figure 4). Bicontinuous cubic phases are geometrically well defined, based on mathematically minimal surfaces of primitive (P), diamond (D) and gyroid (G) type [24]. The continuous bilayer is draped around these surfaces separating two aqueous networks, forming corresponding cubic phases with crystallographic groups of $\operatorname{Im} 3 \mathrm{~m}$, Pn3m and Ia3d [24,25] (Figure 4). These phases are called "bi"-continuous owing to their continuity in aqueous as well as lipid bilayer networks. The sponge phase $\left(L_{3}\right)$ is also bicontinuous in nature but the bilayer is not well-ordered as in cubic phases [26-28] (Figure 4). Bicelles [29], bicontinuous cubic [30] and sponge [31] phases are very useful for biotechnological applications, for instance, for reconstitution and crystallization of membrane proteins. But more interestingly, bicontinous cubic and hexagonal phase structures have been recognized as "biomimetic" as they were seen in sub-cellular membranes of endoplasmic reticulum, Golgi and mitochondria [32,33]. Micellar phases are formed of discrete micelles ordered on a regular lattice [34,35]. The Fd3m phase is an example of micellar cubic phase consisting of two different sized micelles ordered on a cubic lattice [36] (Figure 4). Similar to bicelles, this phase is also adopted by a mixture of components rather than pure lipid-water systems [36]. Above lipid nanostructures are categorized as thermodynamically stable phases under equilibrium conditions. Most common lipid phases are discussed above, however there are some other phases-either intermediate or metastable and not commonly found (for details, readers are advised to refer corresponding publications $[27,37-40])$.

Topical applications of various bulk self-assembled lipid nanostructures have been successfully demonstrated by several research groups [41-45]. On conventional lipid-water phase diagrams, the bicontinuous cubic phases are generally observed at higher water fractions as compared to lamellar phases [46-48]. This also means that cubic phases show stronger water holding capacity than lamellar nanostructures. It was experimentally demonstrated that the cubic phase containing gel increases water binding to the skin [49]. On the contrary, the cubic phase was shown to be highly vapor permeable leading to more trans-epidermal water loss (TEWL) compared to the lamellar phase applied on human skin [49]. This may be attributed to the open network of water channels in bicontinuous cubic phase. Moreover, the cubic phases are highly viscous and sticky, making them difficult to handle and difficult to apply on skin, whereas the rather anhydrous lamellar phase is fluid and thus easy to apply. Nonetheless, the handling difficulties of viscous phases can be reduced by simply dispersing them into fluid emulsion forms as described in the following section.

\section{Lipid Nanostructured Emulsions: Next Level of Structural Hierarchy}

Self-assembled lipid nanostructures including lamellar, hexagonal and cubic phases are potentially useful for encapsulation of functional molecules [50-57]. Their sustained release applications have been reported recently [51,58-61]. However, these phases, especially cubic phases exhibit very high 
viscosity [62-65], causing difficulties in their precise harvesting and thus handling using conventional techniques. One of the best ways to enhance the applicability of these lipid nanostructures is to disperse them into particulate or less viscous systems [66-68]. The resulting systems display hierarchically ordered morphologies ranging from nanometer to millimeter length scales; for example see [68].

Dispersed systems are usually some form of emulsion; for instance, oil-in-water $(\mathrm{O} / \mathrm{W})$ or water-in-oil (W/O) emulsions of lipid components in an aqueous medium (Figure 5). The O/W emulsions of lipid nanostructures are usually prepared by dispersing lipid (or lipid additive mixture) in an aqueous solution of a stabilizer molecule. For this, the above mixture is subjected to a high energy input, such as ultra-sonication, by which highly viscous liquid crystalline phase is fragmented into discrete particles of micron or sub-micron size [66]. Interface of these particles is then kinetically stabilized by stabilizer molecules keeping them dispersed and thus preventing their further aggregation. The resulting dispersion exhibits water-like fluidity while maintaining self-assembled nanostructures at the cores of dispersed particles. These particles are internally self-assembled, hence they are also called "isasomes" ("somes" here refers to particles) [69]. More specifically, the particles with the cubic self-assembly are called "cubosomes" [66], while "hexosomes" are the particles having an interior of the hexagonal type [70]. It is possible to modulate the internal self-assembly into other nanostructures including lamellar phase, sponge phase, micellar cubic phase and inverse micelles [15]. This is an important distinguishing feature of these nanostructured emulsions from conventional $\mathrm{O} / \mathrm{W}$ emulsions where the oil phase is simply made up of oily droplets-usually fluid and disordered. However, the oil phase in nanostructured emulsions is usually a semi-solid liquid crystalline phase, which is highly ordered in nanometer length scales.
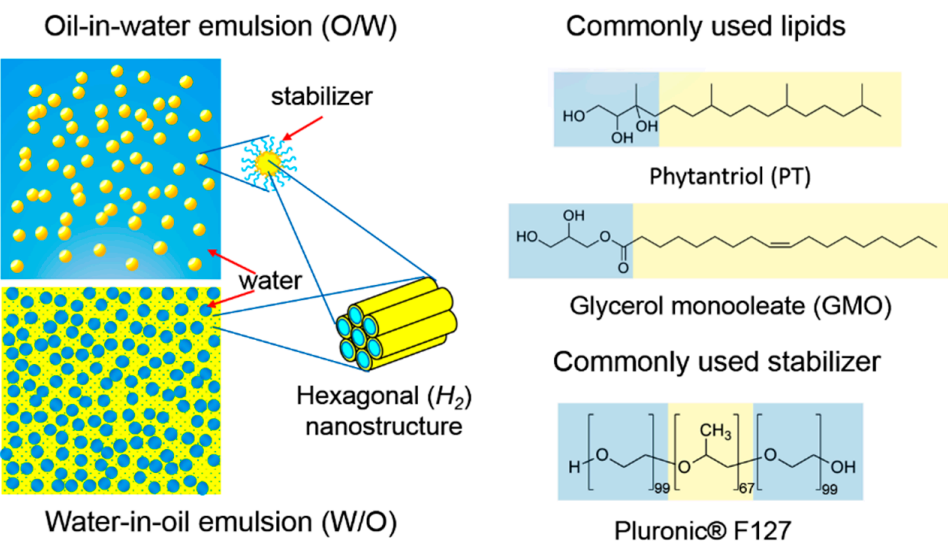

Figure 5. Kinetically stabilized oil-in-water $(\mathrm{O} / \mathrm{W})$ and water-in-oil $(\mathrm{W} / \mathrm{O})$ nanostructured emulsions comprising a self-assembled lipid nanostructure are shown in the left panel. The hexagonal nanostructure is shown as an example but it should be noted that both of these emulsions can be prepared with other types of nanostructures, including bicontinuous cubic Pn3m or Im3m, micellar cubic Fd3m, hexagonal $\left(H_{2}\right)$ or inverse micelles $\left(L_{2}\right)$. Chemical structures of the most common lipids and a stabilizer used to prepare nanostructured emulsions are shown on the right.

The primary components of $\mathrm{O} / \mathrm{W}$ nanostructured emulsions are: lipid, stabilizer and water (Figure 5). The lipids, namely monoolein (MO) and monolinolein (ML), have been utilized in their pure forms or as commercial grades, glycerol monooleate (GMO) and dimodan (DU), respectively. Phytantriol (PT), which is a well-known cosmetic ingredient [71], is becoming popular in preparing nanostructured particle dispersions [60,72-74]. Some other lipids exploited for the preparation of cubosomes include, monoelaidin, myverol, Soy phosphatidylcholine/glycerol dioleate and 1,2-dioleoyl-sn-glycero-3-phosphocholine (DOPC)/1,2-dioleoyl-sn-glycero-3-phosphoethanolamine (DOPE) [74-77]. Recently we have prepared O/W emulsion using a food material, butter oil, which is a cheap and abundant source of lipid molecules [78]. 
A wide range of stabilizers [76] have been used for $\mathrm{O} / \mathrm{W}$ emulsions including surfactants [66], silica nanoparticles [79], clay platelets [80] and carbon nanotubes [81,82]. The pluronic F127, a triblock co-polymer has been very popular stabilizer for nanostructured emulsions among others $[74,83]$ (Figure 5).

$\mathrm{O} / \mathrm{W}$ nanostructured emulsions generally require simple preparation set-ups that can be easily scaled up for commercial production [84-86]. As the nanostructured particles are based on a lipid self-assembly, the availability of lipophilic volume and an interfacial area per particle (up to $400 \mathrm{~m}^{2} / \mathrm{g}$ ) is far greater than the conventional liposomes [50]. This is, in fact, quite advantageous for poorly water soluble functional molecules. $\mathrm{O} / \mathrm{W}$ emulsions show great potential for encapsulating hydrophilic, hydrophobic or amphiphilic molecules, which are presumably hosted in an aqueous continuous medium, lipophilic region with self-assembled lipid nanostructures and native-like bilayer membrane, respectively $[50,74,87]$. It has been demonstrated that these nanostructured particles can be administrated via oral, intravenous, dermal, intradermal, mucosal, ocular, intranasal, percutaneous, intraperitoneal and intra-tympanic routes [74], which is certainly promising for developing cosmetic applications of the above systems. Moreover, the biocompatibility studies of these particles have been performed via interacting with cell membranes, model membranes [88] and blood components [89].

$\mathrm{O} / \mathrm{W}$ emulsions, discussed above, are primarily the lipid self-assemblies dispersed in water taking a colloidal (particulate) form. Conversely, W/O nanostructured emulsions (Figure 5) have these phases reversed, meaning the dispersed phase is water and the continuous phase can be one of the lipid self-assemblies [68,90-93]. The type of self-assembly can be bicontinuous cubic Pn3m or Im3m, micellar cubic $\mathrm{Fd} 3 \mathrm{~m}$, hexagonal $\left(\mathrm{H}_{2}\right)$ or inverse micelles $\left(L_{2}\right)$ (Figure 5$)$. W/O emulsions are usually very concentrated and their stability is governed by the concentration of the components $[94,95]$. For instance, the emulsion can be stabilized by an optimum concentration of emulsion stabilizer or by obtaining a very high concentration of an internal phase or both of the above. Emulsions containing $>74 \%$ dispersed phase are called high internal phase ratio emulsions (HIPRE) or high internal phase emulsions (HIPE), or alternatively bi-liquid foams or gel emulsions [90,96-99].

Interestingly, one of the recent reports reveal that the $\mathrm{W} / \mathrm{O}$ nanostructured emulsions can be prepared without using any external stabilizer $[68,76,100]$. Moreover, the preparation methodology discussed therein offers a range of possibilities to fine-tune them with respect to their nanostructure and properties. It was anticipated that the emulsion stability is brought by an apparent viscosity of the self-assembled nanostructure (except the emulsion with the $L_{2}$ phase, where the stability is supposed to be imparted by the packing of droplets, similar to HIPRE). These emulsions were prepared using a custom-made device based on high temperature shearing of pre-mixed lipophilic and hydrophilic phases [68]. However, we noticed that these emulsions can be crudely prepared by heating the mixture of lipophilic and hydrophilic phases above melting transition, followed by a rigorous mixing (e.g., using vortex) while they are cooled at room temperature. Exciting advantages of these W/O nanostructures for cosmetic formulations are as follows [68,101]: (1) they can be prepared without any stabilizer thus facilitating the development of surfactant-free cosmetic products; (2) they can imbibe $50-90 \mathrm{wt} \%$ water, ideally suited for an efficient moisturizing agent; (3) they can be prepared via simple lab-based techniques as well as by custom-made scalable technology; (4) they can be made to adopt a range of physical forms designated for cosmetics, for instance, fluid, creamy, paste-like, gel-like or dynamically arrested form [68]; (5) they exhibit hierarchically ordered architectures which offer a great degree of tunability at various levels; and (6) they have an ability to encapsulate functional molecules of hydrophilic, hydrophobic and amphiphilic types.

In addition to the above discussed $\mathrm{O} / \mathrm{W}$ and $\mathrm{W} / \mathrm{O}$ nanostructured emulsions, there are a range of other emulsions [15] including double-emulsions, nano-emulsions, micro-emulsions, poly high internal phase ratio emulsions (polyHIPRE) [102], polymerized lipid self-assemblies [103-106], bicontinuous inter-facially jammed emulsion gels (Bi-jels) [107], liquid crystalline elastomers [108], solid lipid nanoparticles (SLN) [109], and layer-by-layer assemblies involving lipid nanostructures [110]; however, these are not discussed any further. 


\section{Modulating Structure and Properties of Lipid Systems}

Structure, properties and performance of lipid systems are closely linked, therefore it is possible to fine-tune the structure over a broad range and achieve desired properties and a suitable performance. For instance, the internal self-assembly of nanostructured emulsions can be altered from cubic Pn $3 \mathrm{~m}$ to cubic $\operatorname{Im} 3 \mathrm{~m}$ by adding diglycerol monooleate or pluronic F127 to a DU lipid system [111,112]. The size of lipid nanoparticles can be modulated by changing the concentration of the dispersed phase and/or the shear rate of the shearing device [94]. Nanoscale parameters can be moderated further by using a different emulsifying lipid; for instance, GMO and PT can be used for many applications where the DU is demonstrably used $[60,73,113]$. Addition of additives in varying proportions can induce structural changes; the additives can be an oil (tetradecane (TC), $R(+)$ limonene (LM), etc.), glycerol, polysaccharides or other surfactants [50,112,114-118].

The temperature [119,120], the pressure [119], an effective charge $[72,80,121]$ or the $\mathrm{pH}[122]$ can also cause structural transitions in the self-assembled nanostructures of lipid particles. The type of internal nanostructure is important because it can determine the possibility and efficiency of the encapsulation of functional molecules within the lipid system. Moreover, the release rates are strongly influenced by the type and lattice parameters of the nanostructure of lipid systems $[53,60,74]$.

The rheological properties, especially the viscosity and the yield stress, are critical parameters while developing cosmetic products [123]. These properties differ largely among the self-assembled lipid nanostructures and their hierarchically organized derivatives as discussed below (Figure 6). Liposome solutions are usually very diluted and thus display water-like consistency. On the other hand, the viscosity (or storage modulus) of self-assembled bulk phases broadly increases from $L_{\alpha}$ phase to $\mathrm{H}_{2}$ phase to bicontinuous cubic phases [65,124], providing them viscous gel-like consistency (Figure 6). The dispersed system of nanostructured lipid particles (O/W emulsions) exhibits rather low viscosity (milk-like consistency) (Figure 6), which is actually one of the main motivations behind their preparation. Nonetheless, these $\mathrm{O} / \mathrm{W}$ emulsions can be made viscous, if required, by various means, for instance, by increasing the concentration of the dispersed phase (usually a lipid phase) [94] or by preparing a hydrogel in the continuous phase of these emulsions $[125,126]$ (Figure 6). The latter can be employed to partially arrest the dynamics of the nanostructured lipid particles [125]. This mixed system can be subsequently dehydrated to obtain dry films where the lipid particles are fully immobilized [127] (Figure 6). These thermos-reversible hydrogel systems can be rehydrated and re-dispersed on demand, which is highly useful for their storage, transport and potential biotechnological applications [128].

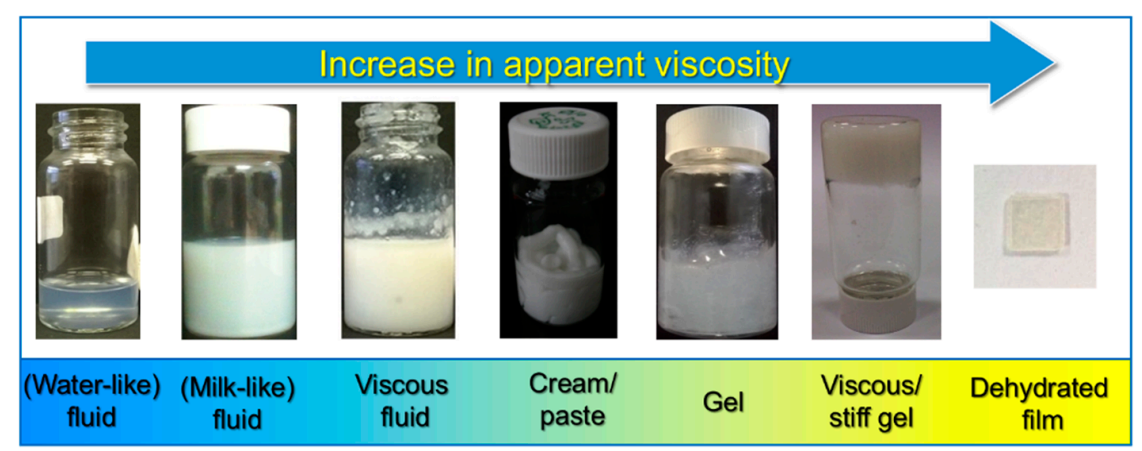

Figure 6. Apparent viscosity and virtual appearance of lipid-based systems. From left to right: liposome solution, $\mathrm{O} / \mathrm{W}$ nanostructured emulsion, dense $\mathrm{O} / \mathrm{W}$ water nanostructured emulsion, $\mathrm{W} / \mathrm{O}$ nanostructured emulsion, bicontinuous cubic phase of a lipid, $\mathrm{O} / \mathrm{W}$ water emulsion with a hydrogelator (does not fall due to gravity) and a film made by dehydrating the $\mathrm{O} / \mathrm{W}$ water emulsion with a hydrogelator. All of these samples were prepared in the author's laboratory at different times.

The $\mathrm{W} / \mathrm{O}$ nanostructured emulsions exist in a range of consistencies including fluid, gel and cream, and also offer a great tunability in terms of their apparent viscosity $[68,101]$. Apparent viscosity 
(and yield stress) can be controlled by varying the dispersed phase content $(\phi)$, the proportion of the lipid phase (given in terms of $\delta$ value) and the concentration of hydrogelator $(\varepsilon$ ), as illustrated in Figure 7 [68]. Other parameters including temperature, type of nanostructure and type of lipid also influence the viscoelastic behavior of these nanostructured emulsions $[68,101]$.
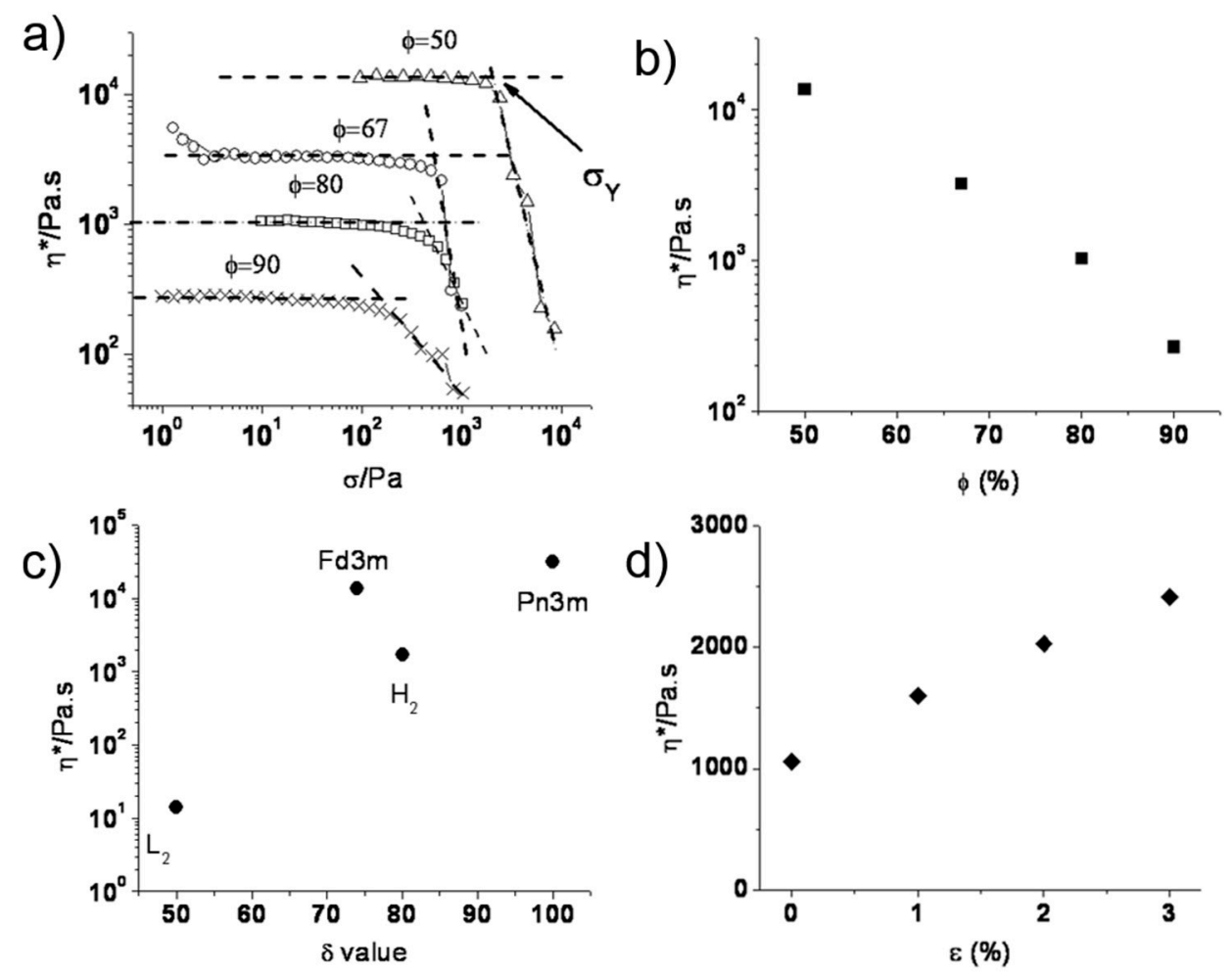

e)

$$
\begin{aligned}
& \delta=\frac{m_{\text {lipid }}}{m_{\text {lipid }}+m_{\text {oil }}} \times 100 \\
& \phi=\frac{m_{\text {Water }}}{m_{\text {Lipid }}+m_{\text {Oil }}+m_{\text {Water }}} \times 100
\end{aligned}
$$

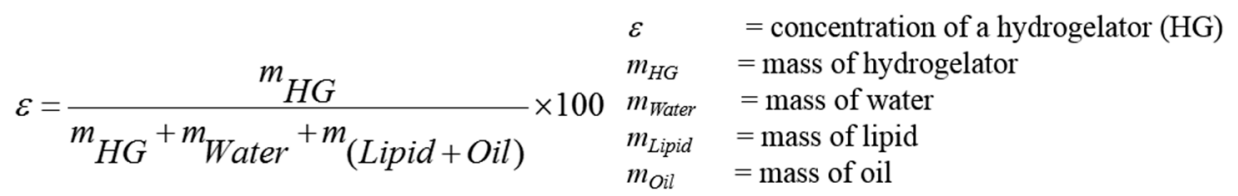

$$
\begin{aligned}
& \delta=\text { lipid concentration in a lipophilic phase } \\
& m_{\text {Lipid }} \quad=\text { mass of lipid } \\
& m_{\text {Oil }} \quad=\text { mass of oil } \\
& \phi \quad=\text { concentration of a dispersed phase } \\
& m_{\text {Water }}=\text { mass of water } \\
& m_{\text {Lipid }} \quad=\text { mass of lipid } \\
& m_{\text {Oil }} \quad=\text { mass of oil }
\end{aligned}
$$

Figure 7. Controlling the yield stress (a) and the viscosity of $\mathrm{W} / \mathrm{O}$ emulsions by changing the concentration of dispersed phase, $\phi(\mathbf{a}, \mathbf{b})$, the $\delta$ value influencing the type of lipid nanostructure (c), and the concentration of hydrogelator, $\varepsilon$ (d); Figure modified from [68]; (e) Definition of terms displayed in above graphs (a) to (d). $\eta^{*}$ represents a complex viscosity, $\sigma$ represents shear stress and $\sigma_{Y}$ represents yield stress.

\section{Nano-Hybrid Systems Based on Lipid Nanostructures}

Recently, we have employed a very different approach to prepare $\mathrm{O} / \mathrm{W}$ nanostructured emulsions. We developed these lipid-based systems by using a variety of carbon nanotubes (single-walled, hydroxyl-functionalized multi-walled and carboxyl-functionalized multi-walled) as stabilizers [81,82] (Figure 8). Another hybrid system was prepared from a different elegant carbon nanomaterial, 
fullerene $\left(\mathrm{C}_{60}\right)$. The $\mathrm{C}_{60}$ was incorporated in the F127-stabilized O/W nanoparticle system [129] (Figure 8). Although these hybrid nano-systems might be considered non-biocompatible, they could be potential candidates for developing novel and innovative applications in future. The apparent reason is that the toxicity of pristine carbon nanomaterials is presumed to be greatly reduced by coating them with the lipid molecules, which are already biogenic materials. Similar efforts were also made by other researchers who managed to stabilize $\mathrm{O} / \mathrm{W}$ nanostructured emulsions using silica nanoparticles [72] and laponite or montmorillonite clay platelets [80,130,131]. As mentioned earlier, we were also able to construct lipid-hydrogel hybrid systems and demonstrate their potential for loading and release of functional molecules in a sustained manner [128] (Figure 8).

a)

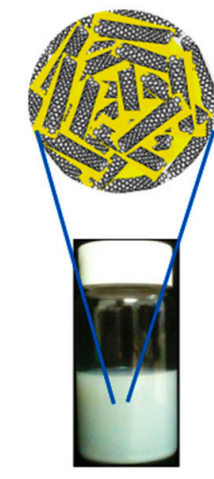

CNT-stabilized

O/W nanostructured emulsion b)

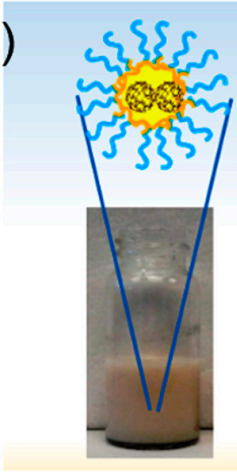

$\mathrm{C}_{60}$ loaded

$\mathrm{O} / \mathrm{W}$ nanostructured emulsion

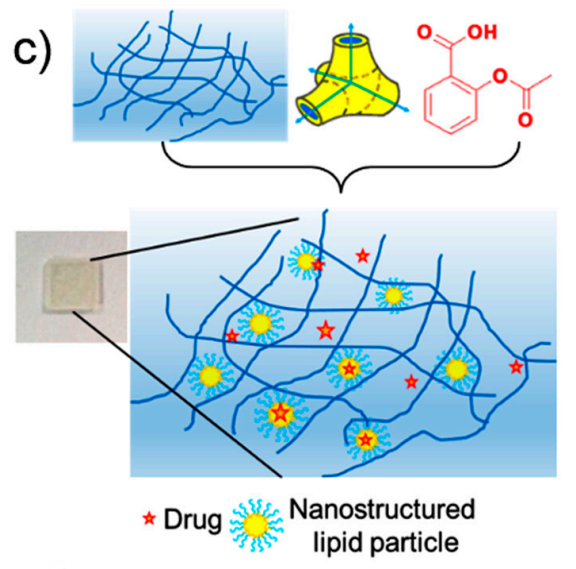

Self-assembled lipid nanostructure ${ }^{\kappa-C a r r a g e e n a n}$

Figure 8. Lipid-based nano-hybrid systems prepared using (a) carbon nanotubes (CNTs); (b) fullerene $\left(\mathrm{C}_{60}\right)$ and $(\mathbf{c}) \mathrm{K}$-carrageenan $(\mathrm{KC})$ as a hydrogelator (and a drug, aspirin).

These novel nanocomposite systems appear to be highly promising for future cosmetic applications as they could benefit from the special characteristics of both "lipid nanostructures" and the "other component, i.e., $\mathrm{CNT}, \mathrm{C}_{60}$, silica nanoparticle, clay platelet or hydrogel". It is thus possible to load them with more than one active ingredient, thereby opening new avenues in terms of simultaneous delivery of multiple molecules.

\section{Conclusions and Perspectives}

This report collectively describes a range of lipid-based systems including the basic self-assembly, hierarchically organized systems, novel food-based emulsion and nano-hybrid lipid systems. The review is not comprehensive but provides a different approach to the existing lipid-based materials and sheds light on their potential development into various cosmetic products by fine-tuning their properties at various levels.

Conflicts of Interest: The authors declare no conflict of interest.

\section{References}

1. EU-Regulation. Regulation (ec) No 1223/2009 of the European Parliament and of the Council of 30 November 2009 on Cosmetic Products (Recast); The European Parliament and the Council: Brussels, Belgium, 2009; Volume 1223.

2. Ingredients-Inventory. Ingredients/Fragrance Inventory (Cosing 2); European Commission: Brussels, Belgium, 2016.

3. Lautenschläger, H. Lipophilic substances-Oils and lipids in cosmetic products. Kosmet. Int. 2004, 4, 46-48.

4. Hernandez, E. Pharmaceutical and cosmetic use of lipids. In Bailey's Industrial Oil and Fat Products; John Wiley \& Sons, Inc.: Hoboken, NJ, USA, 2005. 
5. Hernandez, E. Lipids, pharmaceutical and cosmetic use. In Kirk-Othmer Encyclopedia of Chemical Technology; John Wiley \& Sons, Inc.: Hoboken, NJ, USA, 2000.

6. Alvarez, A.M.R.; Rodríguez, M.L.G. Lipids in pharmaceutical and cosmetic preparations. Grasas Aceites 2000, 51, 74-96.

7. Lipid Maps Structure Database (LMSD). Lipidomics Gateway. 2015. Available online: www.lipidmaps.org (accessed on 28 October 2016).

8. Luzzati, V.; Tardieu, A. Lipid phases: Structure and structural transitions. Annu. Rev. Phys. Chem. 1974, 25, 79-94. [CrossRef]

9. Larsson, K.; Fontell, K.; Krog, N. Structural relationships between lamellar, cubic and hexagonal phases in monoglyceride-water systems. Possibility of cubic structures in biological systems. Chem. Phys. Lipids 1980, 27, 321-328. [CrossRef]

10. Seddon, J.M. Structure of the inverted hexagonal (HII) phase, and non-lamellar phase transitions of lipids. Biochim. Biophys. Acta 1990, 1031, 1-69. [CrossRef]

11. Israelachvili, J. Intermolecular and Surface Forces; Academic Press: London, UK, 1991.

12. Kumar, V.V. Complementary molecular shapes and additivity of the packing parameter of lipids. Proc. Natl. Acad. Sci. USA 1991, 88, 444-448. [CrossRef] [PubMed]

13. Israelachvili, J.N.; Mitchell, D.J.; Ninham, B.W. Theory of self-assembly of lipid bilayers and vesicles. Biochim. Biophys. Acta 1977, 470, 185-201. [CrossRef]

14. Tresset, G. The multiple faces of self-assembled lipidic systems. PMC Biophys. 2009, 2, 3. [CrossRef] [PubMed]

15. Kulkarni, C.V. Lipid crystallization: From self-assembly to hierarchical and biological ordering. Nanoscale 2012, 4, 5779-5791. [CrossRef] [PubMed]

16. Chan, Y.-H.M.; Boxer, S.G. Model membrane systems and their applications. Curr. Opin. Chem. Biol. 2007, 11, 581-587. [CrossRef] [PubMed]

17. Allen, T.M.; Cullis, P.R. Liposomal drug delivery systems: From concept to clinical applications. Adv. Drug Deliv. Rev. 2013, 65, 36-48. [CrossRef] [PubMed]

18. Angelov, B.; Angelova, A.; Drechsler, M.; Garamus, V.M.; Mutafchieva, R.; Lesieur, S. Identification of large channels in cationic pegylated cubosome nanoparticles by synchrotron radiation saxs and cryo-tem imaging. Soft Matter 2015, 11, 3686-3692. [CrossRef] [PubMed]

19. Cheng, A.; Caffrey, M. Interlamellar transition mechanism in model membranes. J. Phys. Chem. B 1996, 100, 5608-5610. [CrossRef]

20. Rhein, L.D.; Schlossman, M.; O'Lenick, A.; Somasundaran, P. Surfactants in Personal Care Products and Decorative Cosmetics, 3rd ed.; CRC- Press: Boca Raton, FL, USA, 2006.

21. Rye, G.G.; Litwinenko, J.W.; Marangoni, A.G. Fat crystal networks. In Bailey's Industrial Oil and Fat Products; John Wiley \& Sons, Inc.: Hoboken, NJ, USA, 2005.

22. Garti, N.; Sato, K. Crystallization Processes in Fats and Lipid Systems; CRC Press: Boca Raton, FL, USA, 2001.

23. Sanders, C.R.; Prosser, R.S. Bicelles: A model membrane system for all seasons? Structure 1998, 6, 1227-1234. [CrossRef]

24. Seddon, J.M.; Templer, R.H. Cubic phases of self-assembled amphiphilic aggregates. Philos. Trans. Math. Phys. Eng. Sci. 1993, 344, 377-401. [CrossRef]

25. Larsson, K. Cubic lipid-water phases: Structures and biomembrane aspects. J. Phys. Chem. 1989, 93, 7304-7314. [CrossRef]

26. Cates, M.E. The isotropic ("sponge") to lamellar transition in dilute surfactant systems. Phys. A Stat. Theor. Phys. 1991, 176, 187-199. [CrossRef]

27. Seddon, J.M.; Templer, R.H. Polymorphism of lipid-water systems. In Handbook of Biological Physics; Lipowsky, R., Sackmann, E., Eds.; Elsevier Science B.V.: Amsterdam, The Netherlands, 1995; Volume 1, pp. 97-160.

28. Engström, S.; Alfons, K.; Rasmusson, M.; Ljusberg-Wahren, H. Solvent-induced sponge $\left(\mathrm{L}_{3}\right)$ phases in the solvent-monoolein-water system. In The Colloid Science of Lipids; Lindmann, B., Ninham, B.W., Eds.; Steinkopff-Verlag: Darmstadt, Germany, 1998; pp. 93-98.

29. Faham, S.; Bowie, J.U. Bicelle crystallization: A new method for crystallizing membrane proteins yields a monomeric bacteriorhodopsin structure. J. Mol. Biol. 2002, 316, 1-6. [CrossRef] [PubMed]

30. Landau, E.M.; Rosenbusch, J.P. Lipidic cubic phases: A novel concept for the crystallization of membrane proteins. Proc. Natl. Acad. Sci. USA 1996, 93, 14532-14535. [CrossRef] [PubMed] 
31. Wadsten, P.; Woehri, A.B.; Snijder, A.; Katona, G.; Gardiner, A.T.; Cogdell, R.J.; Neutze, R.; Engstroem, S. Lipidic sponge phase crystallization of membrane proteins. J. Mol. Biol. 2006, 364, 44-53. [CrossRef] [PubMed]

32. Almsherqi, Z.A.; Landh, T.; Kohlwein, S.D.; Deng, Y. Chapter 6 cubic membranes: The missing dimension of cell membrane organization. In International Review of Cell and Molecular Biology; Kwang, W.J., Ed.; Academic Press: London, UK, 2009; Volume 274, pp. 275-342.

33. Tomas, L. From entangled membranes to eclectic morphologies: Cubic membranes as subcellular space organizers. FEBS Lett. 1995, 369, 13-17.

34. Sakya, P.; Seddon, J.M.; Templer, R.H.; Mirkin, R.J.; Tiddy, G.J.T. Micellar cubic phases and their structural relationships: The nonionic surfactant system C12EO12/water. Langmuir 1997, 13, 3706-3714. [CrossRef]

35. Seddon, J.M.; Robins, J.; Gulik-Krzywicki, T.; Delacroix, H. Inverse micellar phases of phospholipids and glycolipids. Phys. Chem. Chem. Phys. 2000, 2, 4485-4493. [CrossRef]

36. Seddon, J.M.; Zeb, N.; Templer, R.H.; McElhaney, R.N.; Mannock, D.A. An Fd3m lyotropic cubic phase in a binary glycolipid/water system. Langmuir 1996, 12, 5250-5253. [CrossRef]

37. Siegel, D.P. Inverted micellar intermediates and the transitions between lamellar, cubic, and inverted hexagonal amphiphile phases. 3. Isotropic and inverted cubic state formation via intermediates in transitions between 1-alpha and h-ii phases. Chem. Phys. Lipids 1986, 42, 279-301.

38. Kozlovsky, Y.; Chernomordik, L.V.; Kozlov, M.M. Lipid intermediates in membrane fusion: Formation, structure, and decay of hemifusion diaphragm. Biophys. J. 2002, 83, 2634-2651. [CrossRef]

39. Mulet, X.; Gong, X.; Waddington, L.J.; Drummond, C.J. Observation of intermediates in lamellar to cubic phase transformations of lipid nanoparticles. Biophys. J. 2010, 98, 286a-287a. [CrossRef]

40. Shearman, G.C.; Tyler, A.I.I.; Brooks, N.J.; Templer, R.H.; Ces, O.; Law, R.V.; Seddon, J.M. A 3-d hexagonal inverse micellar lyotropic phase. J. Am. Chem. Soc. 2009, 131, 1678-1679. [CrossRef] [PubMed]

41. Bender, J.; Simonsson, C.; Smedh, M.; Engstrom, S.; Ericson, M.B. Lipid cubic phases in topical drug delivery: Visualization of skin distribution using two-photon microscopy. J. Control. Release 2008, 129, 163-169. [CrossRef] [PubMed]

42. Lopes, L.B.; Lopes, J.L.; Oliveira, D.C.; Thomazini, J.A.; Garcia, M.T.; Fantini, M.C.; Collett, J.H.; Bentley, M.V. Liquid crystalline phases of monoolein and water for topical delivery of cyclosporin a: Characterization and study of in vitro and in vivo delivery. Eur. J. Pharm. Biopharm. 2006, 63, 146-155. [CrossRef] [PubMed]

43. Bender, J.; Ericson, M.B.; Merclin, N.; Iani, V.; Rosen, A.; Engstrom, S.; Moan, J. Lipid cubic phases for improved topical drug delivery in photodynamic therapy. J. Control. Release 2005, 106, 350-360. [CrossRef] [PubMed]

44. Turchiello, R.F.; Vena, F.C.; Maillard, P.; Souza, C.S.; Bentley, M.V.; Tedesco, A.C. Cubic phase gel as a drug delivery system for topical application of 5-ALA, its ester derivatives and $\mathrm{m}$-THPC in photodynamic therapy (PDT). J. Photochem. Photobiol. 2003, 70, 1-6. [CrossRef]

45. Esposito, E.; Eblovi, N.; Rasi, S.; Drechsler, M.; Di Gregorio, G.M.; Menegatti, E.; Cortesi, R. Lipid-based supramolecular systems for topical application: A preformulatory study. AAPS PharmSci 2003, 5, 62-76. [CrossRef] [PubMed]

46. Kulkarni, C.V.; Wachter, W.; Iglesias, G.R.; Engelskirchen, S.; Ahualli, S. Monoolein: A magic lipid? Phys. Chem. Chem. Phys. 2011, 13, 3004-3021. [CrossRef] [PubMed]

47. Kulkarni, C.V. Nanostructural studies on monoelaidin-water systems at low temperatures. Langmuir 2011, 27, 11790-11800. [CrossRef] [PubMed]

48. Kulkarni, C.V.; Tang, T.Y.; Seddon, A.M.; Seddon, J.M.; Ces, O.; Templer, R.H. Engineering bicontinuous cubic structures at the nanoscale-The role of chain splay. Soft Matter 2010, 6, 3191-3194. [CrossRef]

49. Spicer, P.; Lynch, M.; Visscher, M.; Hoath, S. Bicontinuous cubic liquid crystalline phase and cubosome personal care delivery systems. In Personal Care Delivery Systems and Formulations; Rosen, M., Ed.; Noyes Publishing: New York, NY, USA, 2003.

50. Yaghmur, A.; Glatter, O. Characterization and potential applications of nanostructured aqueous dispersions. Adv. Colloid Interface Sci. 2009, 147-148, 333-342. [CrossRef] [PubMed]

51. Nazaruk, E.; Miszta, P.; Filipek, S.; Górecka, E.; Landau, E.M.; Bilewicz, R. Lyotropic cubic phases for drug delivery: Diffusion and sustained release from the mesophase evaluated by electrochemical methods. Langmuir 2015, 31, 12753-12761. [CrossRef] [PubMed] 
52. Chen, Y.; Ma, P.; Gui, S. Cubic and hexagonal liquid crystals as drug delivery systems. BioMed Res. Int. 2014, 2014, 815981. [CrossRef] [PubMed]

53. Negrini, R.; Mezzenga, R. Diffusion, molecular separation, and drug delivery from lipid mesophases with tunable water channels. Langmuir 2012, 28, 16455-16462. [CrossRef] [PubMed]

54. Sagalowicz, L.; Leser, M.E.; Watzke, H.J.; Michel, M. Monoglyceride self-assembly structures as delivery vehicles. Trends Food Sci. Technol. 2006, 17, 204-214. [CrossRef]

55. Makai, M.; Csanyi, E.; Nemeth, Z.; Palinkas, J.; Eros, I. Structure and drug release of lamellar liquid crystals containing glycerol. Int. J. Pharm. 2003, 256, 95-107. [CrossRef]

56. Shah, J.; Sadhale, Y.; Chilukuri, D.M. Cubic phase gels as drug delivery systems. Adv. Drug Deliv. Rev. 2001, 47, 229-250. [CrossRef]

57. Engström, S. Drug delivery from cubic and other lipid-water phases. Lipid Technol. 1990, 2, $42-45$.

58. Chemelli, A.; Maurer, M.; Geier, R.; Glatter, O. Optimized loading and sustained release of hydrophilic proteins from internally nanostructured particles. Langmuir 2012, 28, 16788-16797. [CrossRef] [PubMed]

59. Rizwan, S.B.; Boyd, B.J.; Rades, T.; Hook, S. Bicontinuous cubic liquid crystals as sustained delivery systems for peptides and proteins. Expert Opin. Drug Deliv. 2010, 7, 1133-1144. [CrossRef] [PubMed]

60. Lee, K.W.Y.; Nguyen, T.H.; Hanley, T.; Boyd, B.J. Nanostructure of liquid crystalline matrix determines in vitro sustained release and in vivo oral absorption kinetics for hydrophilic model drugs. Int. J. Pharm. 2009, 365, 190-199. [CrossRef] [PubMed]

61. Boyd, B.J.; Whittaker, D.V.; Khoo, S.M.; Davey, G. Lyotropic liquid crystalline phases formed from glycerate surfactants as sustained release drug delivery systems. Int. J. Pharm. 2006, 309, 218-226. [CrossRef] [PubMed]

62. Roux, D.; Nallet, F.; Diat, O. Rheology of lyotropic lamellar phases. Europhys. Lett. 1993, 24, 53-58. [CrossRef]

63. Berni, M.G.; Lawrence, C.J.; Machin, D. A review of the rheology of the lamellar phase in surfactant systems. Adv. Colloid Interface Sci. 2002, 98, 217-243. [CrossRef]

64. Rodriguez-Abreu, C.; Garcia-Roman, M.; Kunieda, H. Rheology and dynamics of micellar cubic phases and related emulsions. Langmuir 2004, 20, 5235-5240. [CrossRef] [PubMed]

65. Mezzenga, R.; Meyer, C.; Servais, C.; Romoscanu, A.I.; Sagalowicz, L.; Hayward, R.C. Shear rheology of lyotropic liquid crystals: A case study. Langmuir 2005, 21, 3322-3333. [CrossRef] [PubMed]

66. Gustafsson, J.; Ljusberg-Wahren, H.; Almgren, M.; Larsson, K. Cubic lipid-water phase dispersed into submicron particles. Langmuir 1996, 12, 4611-4613. [CrossRef]

67. Gustafsson, J.; Ljusberg-Wahren, H.; Almgren, M.; Larsson, K. Submicron particles of reversed lipid phases in water stabilized by a nonionic amphiphilic polymer. Langmuir 1997, 13, 6964-6971. [CrossRef]

68. Kulkarni, C.V.; Mezzenga, R.; Glatter, O. Water-in-oil nanostructured emulsions: Towards the structural hierarchy of liquid crystalline materials. Soft Matter 2010, 6, 5615-5624. [CrossRef]

69. Yaghmur, A.; de Campo, L.; Sagalowicz, L.; Leser, M.E.; Glatter, O. Emulsified microemulsions and oil-containing liquid crystalline phases. Langmuir 2005, 21, 569-577. [CrossRef] [PubMed]

70. Boyd, B.J.; Whittaker, D.V.; Khoo, S.M.; Davey, G. Hexosomes formed from glycerate surfactants-Formulation as a colloidal carrier for irinotecan. Int. J. Pharm. 2006, 318, 154-162. [CrossRef] [PubMed]

71. Mclain, V.C. Final report on the safety assessment of phytantriol. Int. J. Toxicol. 2007, 26 (Suppl. 1), 107-114.

72. Salonen, A.; Muller, F.O.; Glatter, O. Internally self-assembled submicrometer emulsions stabilized by spherical nanocolloids: Finding the free nanoparticles in the aqueous continuous phase. Langmuir 2010, 26, 7981-7987. [CrossRef] [PubMed]

73. Nguyen, T.H.; Hanley, T.; Porter, C.J.; Larson, I.; Boyd, B.J. Phytantriol and glyceryl monooleate cubic liquid crystalline phases as sustained-release oral drug delivery systems for poorly water soluble drugs I. Phase behaviour in physiologically-relevant media. J. Pharm. Pharmacol. 2010, 62, 844-855. [PubMed]

74. Chong, J.Y.T.; Mulet, X.; Boyd, B.J.; Drummond, C.J. Chapter five-Steric stabilizers for cubic phase lyotropic liquid crystal nanodispersions (cubosomes). In Advances in Planar Lipid Bilayers and Liposomes; Aleš Iglič, C.V.K., Michael, R., Eds.; Academic Press: London, UK, 2015; Volume 21, pp. 131-187.

75. Yaghmur, A.; Laggner, P.; Almgren, M.; Rappolt, M. Self-assembly in monoelaidin aqueous dispersions: Direct vesicles to cubosomes transition. PLoS ONE 2008, 3, e3747. [CrossRef] [PubMed]

76. Kulkarni, C.V.; Glatter, O. Hierarchically organized systems based on liquid crystalline phases. In Self-Assembled Supramolecular Architectures: Lyotropic Liquid Crystals; Garti, N., Ed.; John Wiley \& Sons, Inc.: Hoboken, NJ, USA, 2012. 
77. Kulkarni, C.V. Hierarchically structured lipid systems. In Encyclopaedia of Biophysics; Roberts, G.C., Ed.; Springer: Berlin, Germany, 2012.

78. Kulkarni, C.V. Ultrasonic processing of butter oil (Ghee) into oil-in-water emulsions. J. Food Process. Preserv. 2016, in press.

79. Dulle, M.; Glatter, O. Internally self-assembled submicrometer emulsions stabilized with a charged polymer or with silica particles. Langmuir 2011, 28, 1136-1141. [CrossRef] [PubMed]

80. Muller, F.; Salonen, A.; Glatter, O. Phase behavior of phytantriol/water bicontinuous cubic Pn3m cubosomes stabilized by laponite disc-like particles. J. Colloid Interface Sci. 2010, 342, 392-398. [CrossRef] [PubMed]

81. Patil-Sen, Y.; Sadeghpour, A.; Rappolt, M.; Kulkarni, C.V. Facile preparation of internally self-assembled lipid particles stabilized by carbon nanotubes. J. Vis. Exp. 2016, 108, e53489. [CrossRef] [PubMed]

82. Gaunt, N.P.; Patil-Sen, Y.; Baker, M.J.; Kulkarni, C.V. Carbon nanotubes for stabilization of nanostructured lipid particles. Nanoscale 2015, 7, 1090-1095. [CrossRef] [PubMed]

83. Tilley, A.J.; Drummond, C.J.; Boyd, B.J. Disposition and association of the steric stabilizer pluronic ${ }^{\circledR} \mathrm{f} 127$ in lyotropic liquid crystalline nanostructured particle dispersions. J. Colloid Interface Sci. 2013, 392, 288-296. [CrossRef] [PubMed]

84. Spicer, P. Cubosome processing-Industrial nanoparticle technology development. Chem. Eng. Res. Des. 2005, 83, 1283-1286. [CrossRef]

85. Spicer, P.T. Cubosomes: Bicontinuous cubic liquid crystalline nanostructured particles. In Encyclopedia of Nanoscience and Nanotechnology; Marcel Dekker: New York, NY, USA, 2004.

86. Garg, G.; Saraf, S.; Saraf, S. Cubosomes: An overview. Biol. Pharm. Bull. 2007, 30, 350-353. [CrossRef] [PubMed]

87. Angelova, A.; Angelov, B.; Mutafchieva, R.; Lesieur, S.; Couvreur, P. Self-assembled multicompartment liquid crystalline lipid carriers for protein, peptide, and nucleic acid drug delivery. Acc. Chem. Res. 2011, 44, 147-156. [CrossRef] [PubMed]

88. Barauskas, J.; Cervin, C.; Jankunec, M.; Špandyreva, M.; Ribokaitè, K.; Tiberg, F.; Johnsson, M. Interactions of lipid-based liquid crystalline nanoparticles with model and cell membranes. Int. J. Pharm. 2010, 391, $284-291$. [CrossRef] [PubMed]

89. Bode, J.C.; Kuntsche, J.; Funari, S.S.; Bunjes, H. Interaction of dispersed cubic phases with blood components. Int. J. Pharm. 2013, 448, 87-95. [CrossRef] [PubMed]

90. Caldero, G.; Llinas, M.; Garcia-Celma, M.J.; Solans, C. Studies on controlled release of hydrophilic drugs from W/O high internal phase ratio emulsions. J. Pharm. Sci. 2009, 99, 701-711. [CrossRef] [PubMed]

91. Solans, C.; Esquena, J. Highly concentrated (gel) emulsions as reaction media for the preparation of advanced materials. In Highlights in Colloid Science; Platikanov, D., Exerowa, D., Eds.; Wiley-VCH Verlag GmbH \& Co. KGaA: Weinheim, Germany, 2008; pp. 291-297.

92. Solans, C.; Esquena, J.; Azemar, N. Highly concentrated (gel) emulsions, versatile reaction media. Curr. Opin. Colloid Interface Sci. 2003, 8, 156-163. [CrossRef]

93. Solans, C.; Pinazo, A.; Calderó, G.; Infante, M.R. Highly concentrated emulsions as novel reaction media. Colloids Surf. A 2001, 176, 101-108. [CrossRef]

94. Salentinig, S.; Yaghmur, A.; Guillot, S.; Glatter, O. Preparation of highly concentrated nanostructured dispersions of controlled size. J. Colloid Interface Sci. 2008, 326, 211-220. [CrossRef] [PubMed]

95. Paruta-Tuarez, E.; Fersadou, H.; Sadtler, V.; Marchal, P.; Choplin, L.; Baravian, C.; Castel, C. Highly concentrated emulsions: 1 . Average drop size determination by analysis of incoherent polarized steady light transport. J. Colloid Interface Sci. 2010, 346, 136-142. [PubMed]

96. Cameron, N.R. High internal phase emulsion templating as a route to well-defined porous polymers. Polymer 2005, 46, 1439-1449. [CrossRef]

97. Pons, R.; Ravey, J.C.; Sauvage, S.; Stébé, M.J.; Erra, P.; Solans, C. Structural studies on gel emulsions. Colloids Surf. A 1993, 76, 171-177. [CrossRef]

98. Kunieda, H.; Evans, D.F.; Solans, C.; Yoshida, M. The structure of gel-emulsions in a water/nonionic surfactant/oil system. Colloids Surf. 1990, 47, 35-43. [CrossRef]

99. Hunter, T.N.; Pugh, R.J.; Franks, G.V.; Jameson, G.J. The role of particles in stabilising foams and emulsions. Adv. Colloid Interface Sci. 2008, 137, 57-81. [CrossRef] [PubMed] 
100. Kulkarni, C.V.; Iglesias, G.R.; Glatter, O. Nanostructured water in oil emulsions with high water content formed without stabilizer. In Proceedings of the International Soft Matter Conference 2010, Granada, Spain, 5-8 July 2010.

101. Glatter, O.; Glatter, I. Water-in-Oil Emulsions and Methods for Their Preparation. US4,380,503 A, 19 April 1983.

102. Sergienko, A.Y.; Tai, H.; Narkis, M.; Silverstein, M.S. Polymerized high internal-phase emulsions: Properties and interaction with water. J. Appl. Polym. Sci. 2002, 84, 2018-2027. [CrossRef]

103. Forney, B.S.; Guymon, C.A. Nanostructure evolution during photopolymerization in lyotropic liquid crystal templates. Macromolecules 2010, 43, 8502-8510. [CrossRef]

104. Srisiri, W.; Benedicto, A.; O'Brien, D.F.; Trouard, T.P.; Orädd, G.; Persson, S.; Lindblom, G. Stabilization of a bicontinuous cubic phase from polymerizable monoacylglycerol and diacylglycerol. Langmuir 1998, 14, 1921-1926. [CrossRef]

105. Yang, D.; O’Brien, D.F.; Marder, S.R. Polymerized bicontinuous cubic nanoparticles (cubosomes) from a reactive monoacylglycerol. J. Am. Chem. Soc. 2002, 124, 13388-13389. [CrossRef] [PubMed]

106. Armitage, B.; Bennett, D.; Lamparski, H.; O’Brien, D. Polymerization and domain formation in lipid assemblies. In Biopolymers Liquid Crystalline Polymers Phase Emulsion; Springer: Berlin, Germany, 1996; Volume 126, pp. 53-84.

107. Cates, M.E.; Clegg, P.S. Bijels: A new class of soft materials. Soft Matter 2008, 4, 2132-2138. [CrossRef]

108. Ohm, C.; Brehmer, M.; Zentel, R. Liquid crystalline elastomers as actuators and sensors. Adv. Mater. 2010, 22, 3366-3387. [CrossRef] [PubMed]

109. Muller, R.H.; Radtke, M.; Wissing, S.A. Nanostructured lipid matrices for improved microencapsulation of drugs. Int. J. Pharm. 2002, 242, 121-128. [CrossRef]

110. Decher, G. Layer-by-layer assembly (putting molecules to work). In Multilayer Thin Films; Wiley-VCH Verlag GmbH \& Co. KGaA: Weinheim, Germany, 2012; pp. 1-21.

111. Guillot, S.; Salentinig, S.; Chemelli, A.; Sagalowicz, L.; Leser, M.E.; Glatter, O. Influence of the stabilizer concentration on the internal liquid crystalline order and the size of oil-loaded monolinolein-based dispersions. Langmuir 2010, 26, 6222-6229. [CrossRef] [PubMed]

112. Yaghmur, A.; de Campo, L.; Sagalowicz, L.; Leser, M.E.; Glatter, O. Control of the internal structure of mlo-based isasomes by the addition of diglycerol monooleate and soybean phosphatidylcholine. Langmuir 2006, 22, 9919-9927. [CrossRef] [PubMed]

113. Dong, Y.D.; Tilley, A.J.; Larson, I.; Lawrence, M.J.; Amenitsch, H.; Rappolt, M.; Hanley, T.; Boyd, B.J. Nonequilibrium effects in self-assembled mesophase materials: Unexpected supercooling effects for cubosomes and hexosomes. Langmuir 2010, 26, 9000-9010. [CrossRef] [PubMed]

114. Mezzenga, R.; Schurtenberger, P.; Burbidge, A.; Michel, M. Understanding foods as soft materials. Nat. Mater. 2005, 4, 729-740. [CrossRef] [PubMed]

115. Sagalowicz, L.; Mezzenga, R.; Leser, M.E. Investigating reversed liquid crystalline mesophases. Curr. Opin. Colloid Interface Sci. 2006, 11, 224-229. [CrossRef]

116. Engelskirchen, S.; Maurer, R.; Glatter, O. Effect of glycerol addition on the internal structure and thermal stability of hexosomes prepared from phytantriol. Colloids Surf. A 2011, 391, 95-100. [CrossRef]

117. Ubbink, J.; Burbidge, A.; Mezzenga, R. Food structure and functionality-A soft matter perspective. Soft Matter 2008, 4, 1569-1581. [CrossRef]

118. Mezzenga, R.; Grigorov, M.; Zhang, Z.; Servais, C.; Sagalowicz, L.; Romoscanu, A.I.; Khanna, V.; Meyer, C. Polysaccharide-induced order-to-order transitions in lyotropic liquid crystals. Langmuir 2005, 21, 6165-6169. [CrossRef] [PubMed]

119. Yaghmur, A.; Kriechbaum, M.; Amenitsch, H.; Steinhart, M.; Laggner, P.; Rappolt, M. Effects of pressure and temperature on the self-assembled fully hydrated nanostructures of monoolein-oil systems. Langmuir 2010, 26, 1177-1185. [CrossRef] [PubMed]

120. Guillot, S.; Moitzi, C.; Salentinig, S.; Sagalowicz, L.; Leser, M.E.; Glatter, O. Direct and indirect thermal transitions from hexosomes to emulsified micro-emulsions in oil-loaded monoglyceride-based particles. Colloids Surf. A 2006, 291, 78-84. [CrossRef]

121. Salonen, A.; Muller, F.O.; Glatter, O. Dispersions of internally liquid crystalline systems stabilized by charged disklike particles as pickering emulsions: Basic properties and time-resolved behavior. Langmuir 2008, 24, 5306-5314. [CrossRef] [PubMed] 
122. Salentinig, S.; Sagalowicz, L.; Glatter, O. Self-assembled structures and pka value of oleic acid in systems of biological relevance. Langmuir 2010, 26, 11670-11679. [CrossRef] [PubMed]

123. Al-Bawab, A.; Friberg, S.E. Some pertinent factors in skin care emulsion. Adv. Colloid Interface Sci. 2006, 123-126, 313-322. [CrossRef] [PubMed]

124. Alam, M.M.; Mezzenga, R. Particle tracking microrheology of lyotropic liquid crystals. Langmuir 2011, 27, 6171-6178. [CrossRef] [PubMed]

125. Tomsic, M.; Guillot, S.; Sagalowicz, L.; Leser, M.E.; Glatter, O. Internally self-assembled thermoreversible gelling emulsions: Isasomes in methylcellulose, kappa-carrageenan, and mixed hydrogels. Langmuir 2009, 25, 9525-9534. [CrossRef] [PubMed]

126. Guillot, S.; Tomsic, M.; Sagalowicz, L.; Leser, M.E.; Glatter, O. Internally self-assembled particles entrapped in thermoreversible hydrogels. J. Colloid Interface Sci. 2009, 330, 175-179. [CrossRef] [PubMed]

127. Kulkarni, C.V.; Tomšič, M.; Glatter, O. Immobilization of nanostructured lipid particles in polysaccharide films. Langmuir 2011, 27, 9541-9550. [CrossRef] [PubMed]

128. Kulkarni, C.V.; Moinuddin, Z.; Patil-Sen, Y.; Littlefield, R.; Hood, M. Lipid-hydrogel films for sustained drug release. Int. J. Pharm. 2015, 479, 416-421. [CrossRef] [PubMed]

129. Kulkarni, C.V.; Moinuddin, Z.; Agarwal, Y. Effect of fullerene on the dispersibility of nanostructured lipid particles and encapsulation in sterically stabilized emulsions. J. Colloid Interface Sci. 2016, 480, 69-75. [CrossRef] [PubMed]

130. Muller, F.; Salonen, A.; Glatter, O. Monoglyceride-based cubosomes stabilized by laponite: Separating the effects of stabilizer, ph and temperature. Colloids Surf. A 2010, 358, 50-56. [CrossRef]

131. Guillot, S.; Bergaya, F.; de Azevedo, C.; Warmont, F.; Tranchant, J.F. Internally structured pickering emulsions stabilized by clay mineral particles. J. Colloid Interface Sci. 2009, 333, 563-569. [CrossRef] [PubMed]

(c) 2016 by the author; licensee MDPI, Basel, Switzerland. This article is an open access article distributed under the terms and conditions of the Creative Commons Attribution (CC-BY) license (http:/ / creativecommons.org/licenses/by/4.0/). 